Journal of Bangladesh Academy of Sciences, Vol. 37, No. 1, 33-41, 2013

\title{
OPTICAL AND ELECTRICAL CHARACTERISTICS OF PURE CdS THIN FILMS FOR DIFFERENT THICKNESS
}

\author{
A. HASNAT ${ }^{*}$ AND J. PODDER ${ }^{1}$ \\ Department of Physics, Jagannath University, Dhaka, Bangladesh
}

\begin{abstract}
Conventional spray pyrolysis technique was employed for the preparation of cadmium sulphide $(\mathrm{CdS})$ thin films that deposited onto glass substrates at $573 \mathrm{~K}$ from cadmium acetate and thiourea precursor solution for different deposition time. The surface morphology, compositional study and optical properties of the films have been characterized by Scanning Electron Microscopy (SEM) attached with an EDX and UV spectroscopy, respectively. The SEM micrographs of deposited film showed uniform deposition over the substrate. The EDX spectra of CdS thin films revealed that films are stoichiometric. All the films demonstrated more than $70 \%$ transmittance at wavelengths longer than $600 \mathrm{~nm}$. The optical absorption coefficient $(\alpha)$ of the CdS films was determined from transmittance spectra. For different thickness $(110-250 \mathrm{~nm})$ of the films, the direct band gap was found in the range of $2.15 \sim 2.48 \mathrm{eV}$. Resistivity $(\rho)$ of CdS thin films was measured in the temperature range of 300 to $550 \mathrm{~K}$. Activation energy $(\Delta \mathrm{E})$ was found in the range from 0.047 to $0.078 \mathrm{eV}$.
\end{abstract}

Key words: Spray pyrolysis, CdS, Optical band gap

\section{INTRODUCTION}

The study of transparent conducting sulphide film such as cadmium sulphide (CdS) has been given much effort because of its wide range of technical and industrial applications, especially in the field of optoelectronic devices such as solar cells (Anuar et al. 2008), photo transistors (Takahashi et al. 2002), and diodes (Hong et al. 2005), transparent electrodes (Bagnall et al. 2001), gas sensors (Lozada-Morales and ZelayaAnge 2004), etc. CdS thin films exhibit high transmission in the visible and UV regions. In the last decade, various techniques such as thermal evaporation (Elangovan et al. 2009), sputtering (Korotcenkov et al. 2008), solution growth (Naumov et al. 2006), pulsed laser sputtering (Jachon et al. 2007), activated reactive evaporation and spray pyrolysis deposition (SPD) (Jong-Baek et al. 2009) were employed to prepare thin films of CdS. CdS thin films were deposited by thermal evaporation (Morales-Acevedo et al.

\footnotetext{
* Corresponding author: <hasnat@ $@$ phy.jnu.ac.bd>.

${ }^{1}$ Department of Physics, Bangladesh University of Engineering and Technology (BUET), Dhaka, Bangladesh.
} 
2008) under vacuum onto glass substrates kept at 300 and $473 \mathrm{~K}$. The optical energy band gap was found $2.4 \mathrm{eV}$ (Hong et al. 2005). Thin films of CdS were deposited onto amorphous and fluorine-doped tin oxide (FTO) glass substrate using SPD technique. In this study, direct band gap energy was found $2.26 \mathrm{eV}$. The best performances depend on the surface and interface properties of the deposited films. The excellent features, good controllability, high repeatability and fast response depend on the various deposition parameters like spray rates, molar concentrations, substrate temperatures, and deposition time etc. In recent years, researchers are trying to modify the synthesis procedure with a view to improving the chemical and physical properties of CdS films. In this paper, the authors deposited CdS thin films onto glass substrate by a locally developed SPD technique, because it was more attractive and advantageous for its simplicity, cheapness, low cost of starting material and capability of large area deposition. Detailed optical and electrical properties of $\mathrm{CdS}$ thin films have been investigated for various film thicknesses. The influence of annealing temperature on the film characteristics has been investigated. The authors compared the results of deposited CdS thin films with the characteristics reported by others (Vazquez-Luna et al. 2007).

\section{EXPERIMENTAL}

The spray pyrolysis deposition of CdS thin films was carried out in a locally made reaction chamber. The deposition set up consists of four sections, which include: (a) the precursor solution and carrier gas (air) assembly connected to the spray nozzle, (b) the reaction chamber in which the substrate is heated, (c) the pumping and exhausting gas scrubbing systems, and (d) temperature controller with a copper-constantine thermocouple to control the substrate temperature. In the present work, In order to prepare $\mathrm{CdS}$ thin films the aqueous solution of cadmium acetate $\left[\mathrm{Cd}\left(\mathrm{CH}_{3} \mathrm{COO}\right)_{2} \cdot 2 \mathrm{H}_{2} \mathrm{O}\right]$ and thiourea $\left[\mathrm{NH}_{2} \mathrm{CSNH}_{2}\right]$ were used as a source of $\mathrm{Cd}$ and $\mathrm{S}$, respectively. The solution was sprayed onto pre-cleaned glass substrate. The substrate temperature was maintained constant at $573 \mathrm{~K}$. The normalized distance between the spray nozzle and the substrate was fixed at $29 \mathrm{~cm}$. The pressure of the carrier gas (air) was kept constant at $1 \mathrm{bar}$. The solution flow rate was maintained $0.5 \mathrm{ml} \mathrm{min}-1$ throughout the experiment. Films of various thicknesses were prepared through different deposition times. The possible chemical reaction that takes place on the heated substrate to produce $\mathrm{CdS}$ may be as follows:

$$
\left.\begin{array}{c}
\mathrm{Cd}\left(\mathrm{CH}_{3} \mathrm{COOH}\right)_{2} \cdot 2 \mathrm{H}_{2} \mathrm{O}+ \\
\mathrm{NH}_{2} \mathrm{CSNH}_{2}+\mathrm{H}_{2} \mathrm{O}
\end{array}\right\} \begin{gathered}
300^{\circ} \mathrm{C} \\
-------\mathrm{CdS} \downarrow+\mathrm{CO}_{2} \uparrow+\mathrm{CH}_{4} \uparrow+\text { Steam } \uparrow \\
\text { Decomposes }
\end{gathered}
$$




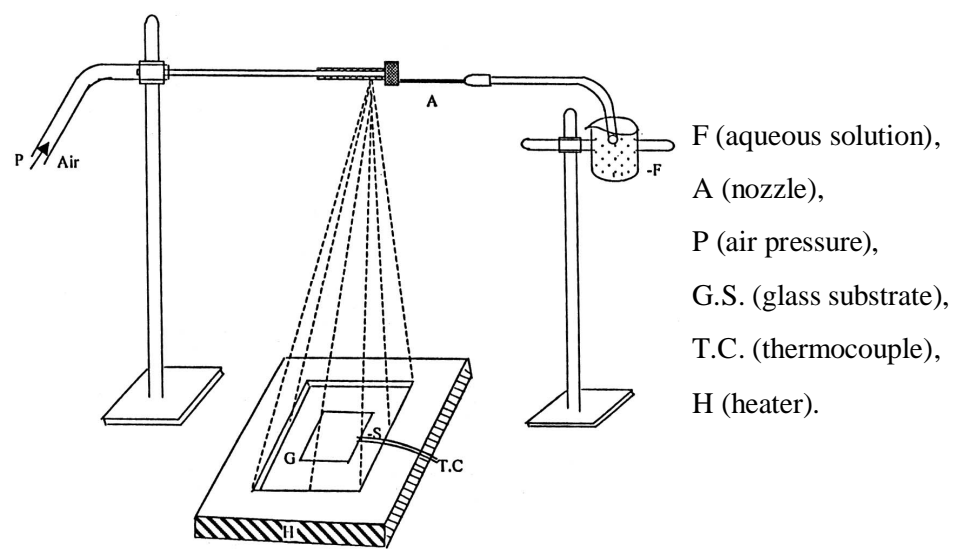

Fig. 1. Spraying aqueous solution on a glass substrate.

Thickness of the films was measured employing interference Newton's ring method. The surface structural properties of the films were examined by Scanning Electron Microscopy (SEM). The optical transmission spectra for deposited CdS thin films of different thicknesses were obtained in the visible region (400 - $1100 \mathrm{~nm})$ using UV-VIS spectrophotometer (Model: pc1601, Shimazdu). The experimental accuracy of the transmittance is $( \pm 0.005 \%)$ and of the wavelength is $( \pm 0.005 \%)$. The observed transmittance data were corrected relative to optically identical uncoated glass substrate. The d.c. electrical resistivity measurements were made in air for deposited films from room temperature to $553 \mathrm{~K}$ by Van der Pauw method and measurements were performed by increasing the temperature slowly of the film. The films were annealed up to a maximum temperature of $550 \mathrm{~K}$ for one hour.

\section{RESULTS AND DISCUSSION}

Surface morphology: Fig. 2 shows SEM of CdS films for different thickness. Here the sprayed particles (atom) are absorbed onto the surface to form clusters as the primary stage of nucleation having higher energy than the individual atoms. Therefore, some spheroid shape appears on the film surfaces. These are most probably aggregated due to colloidal particles formed in solution and then absorbed on the film. Deposited pure CdS film is found more or less smooth, compact, continuous and uniform.

Compositional studies: Fig. 3 shows the EDX spectra of pure CdS thin films. Table 1 shows the composition of elements in film in the sprayed solution. Table 2 shows quantitative results of pure CdS thin films from EDX analysis. In the work the concentration of the total solution was kept fixed at $0.1 \mathrm{M}$. The composition of CdS films was confirmed by energy dispersive X-ray spectroscopy (EDX). Sulphur deficiency was observed in all the films. 


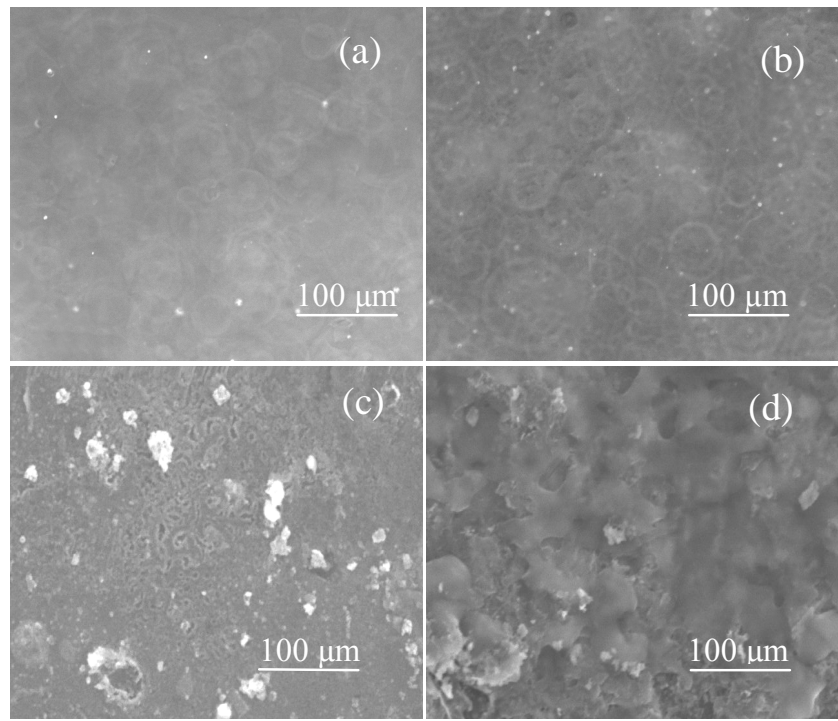

Fig. 2. SEM micrograph of CdS film for (a) $110 \mathrm{~nm}$, (b) $175 \mathrm{~nm}$, (c) $190 \mathrm{~nm}$ and (d) $225 \mathrm{~nm}$.

This may be due to the fact that sulphur has great affinity towards oxygen, so it might have converted to $\mathrm{SO}_{2}$ and then evaporated. A strong peak is observed which corresponds to Si due to substrate. At high operating voltage the electron beam penetrates the film and reaches the glass surface, which results the Si peak. Two different peaks corresponding to $\mathrm{Cd}$ and one $\mathrm{S}$ in the spectrum, which confirms the CdS thin film. EDX result reveals that the deposited films are very close to the nominal composition.

Table 1. Atomic \% of different compositions of CdS thin films.

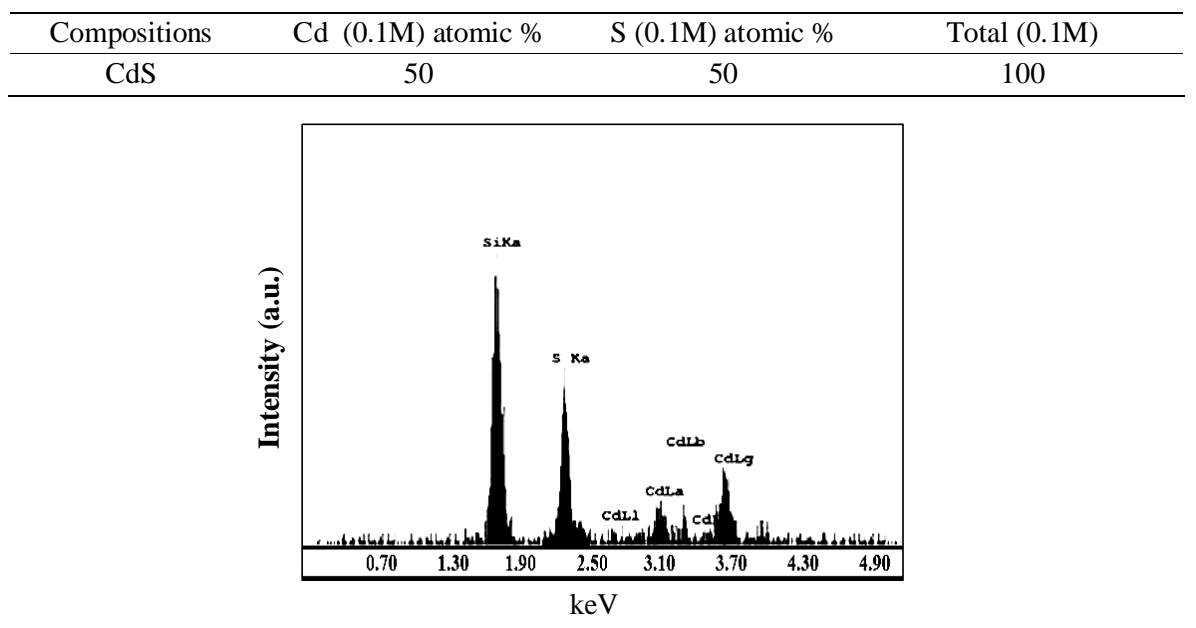

Fig. 3. EDX micrograph of pure CdS thin films on glass substrate. 
Table 2. Quantitative results of pure CdS thin films from EDX analysis.

\begin{tabular}{lllc}
\hline Element & Wt\% & At\% & {$[\mathrm{Cd}] /[\mathrm{S}]$} \\
\hline $\mathrm{Si}$ & 44.47 & 45.82 & \\
$\mathrm{~S}$ & 32.49 & 25.88 & 1.09 \\
$\mathrm{Cd}$ & 23.04 & 28.30 & \\
& 100 & 100 & \\
\hline
\end{tabular}

Transmittance and absorption coefficient: The transmission spectra for as CdS thin films in the wavelength range $(400-1100 \mathrm{~nm})$ are shown in Fig. 4. All the films demonstrated more than $65 \%$ transmittance at wavelengths longer than $500 \mathrm{~nm}$, which is comparable with the values for the CdS thin films deposited using chemical bath deposition method. Below $500 \mathrm{~nm}$ there was a sharp fall in the $\mathrm{T}$ of the films, which was due to the strong absorbance of the films in this region.

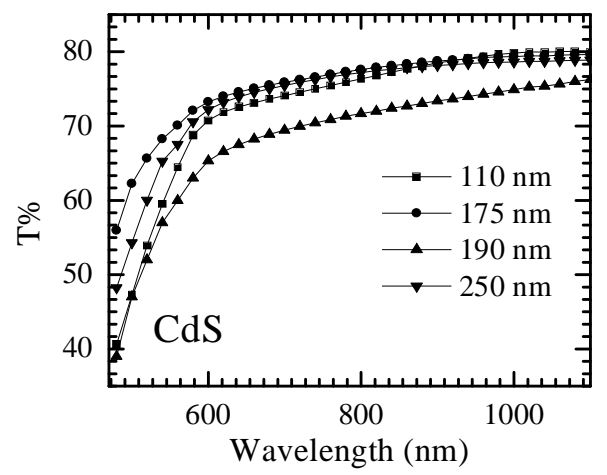

Fig. 4. Variation of transmittance as a function of wavelength for CdS films.

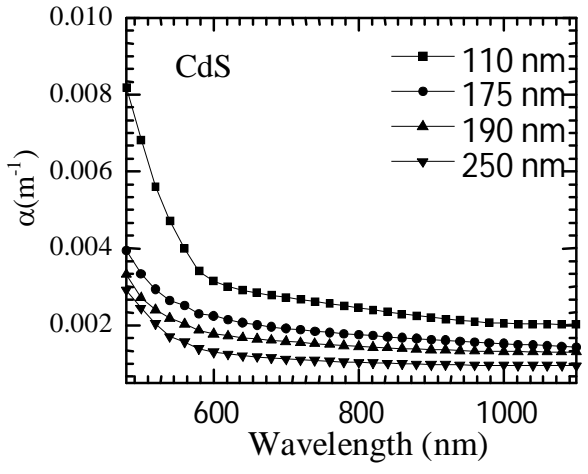

Fig. 5. Variation of $\alpha$ as a function of wavelength for CdS films.

Variation of optical absorption coefficient with wavelength for various film thicknesses is shown in Fig. 5. The absorption coefficient $(\alpha)$ was calculated from the transmittance spectrum using the relation -

$$
\alpha=\frac{\ln \left(\frac{1}{T}\right)}{t} .
$$

where, $T$ is the transmittance and $t$ is the thickness of the film. It shows that the absorption co-efficient increases slowly at the higher wavelength region and then increases sharply near the absorption edge. The absorption co-efficient increases with the thickness of the film strongly with respect to photon energy (hv) demoststrating that the film property is thickness dependent. 
Optical band gap: A plot drawn between $(\alpha h v)^{2}$ versus hv is shown in Fig. 6 . The direct band gap energy of $\mathrm{CdS}$ has been obtained from the intercept of the straight line drawn from $(\alpha h v)^{2}$ versus $h v$ curve on the energy axis. Since CdS is an n-type semiconductor, the band gap decrease with the increase of film thickness, it could be due to the increase of density of localized state in the conduction band. The variation of direct band gap with thickness of CdS thin films are shown in the Fig. 7.

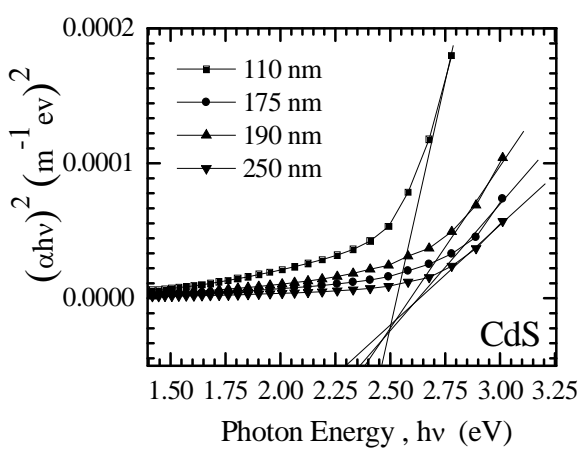

Fig. 6. Variation of $(\alpha h v)^{2}$ vs. photon energy (hv) for CdS films.

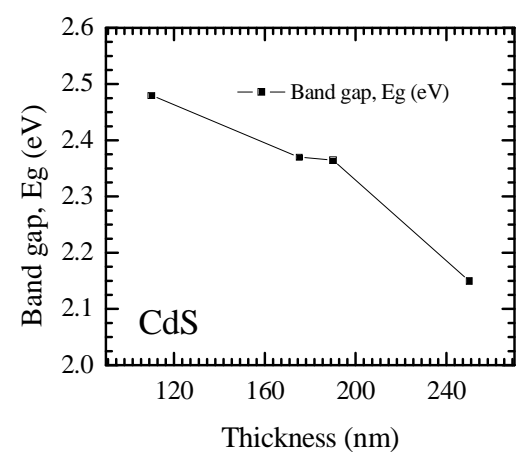

Fig. 7. Variation of direct band gap with thickness for CdS films.

Electrical properties: Fig. 8 shows temperature dependent resistivity for a number of films of different thickness. All films showed similar temperature dependence of resistivity, i.e., a phase change occurs for all films. It can be seen that the position of the maximum resistivity i.e., phase change temperature (TP) shifts gradually towards higher temperature with increase in thickness of the films. Variation of resistivity with temperature during heating, cooling and reheating is shown in Fig. 9. Resistivity showed a non-reversibility behavior in the first heating and cooling cycle.

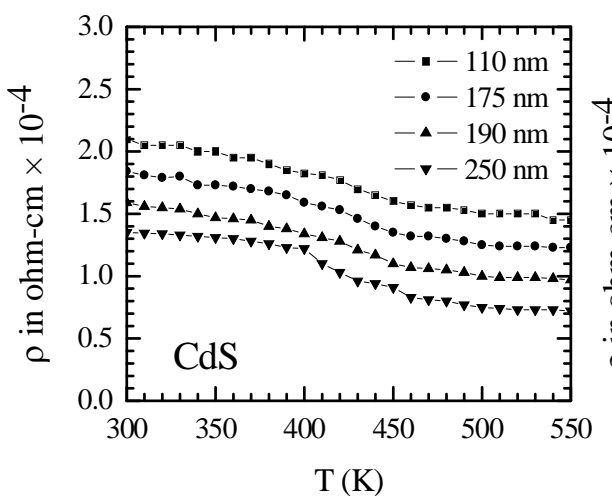

Fig. 8. Variation of electrical resistivity with temperature for CdS films of different thickness.

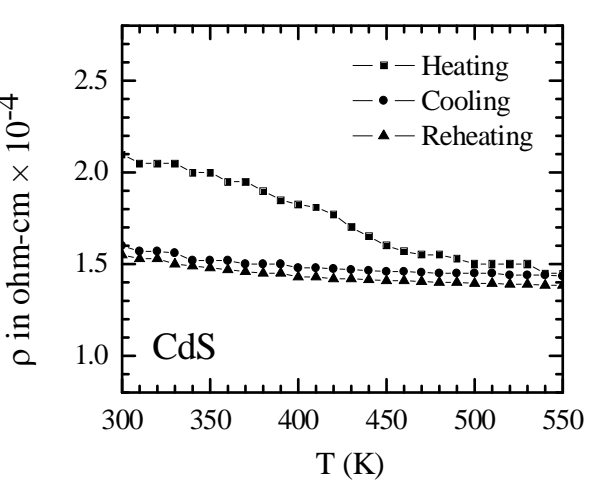

Fig. 9. Variation of resistivity with temperature for $\mathrm{CdS}$ films 
However, resistivity showed reversibility on repeated cycle of heating and cooling and eventually retraces the similar path, indicating a stable state of the sample. The stability of the film seems to be due to the removal of metastable phases, in homogeneity, residual stress and defects that might be present in the prepared samples.

Conductivity of the CdS materials was calculated from the resistivity measurements. The conductivity initially decreases with increase in temperature. The value goes through a minimum and then increases with further increase of temperature. The minimum conductivity is observed near $470 \mathrm{~K}$ and the position of minimum conductivity shifts slowly towards the higher temperature with increase in thickness of the films. The overall conductivity increased with the increase of film thickness. The increase in conductivity due to increasing thickness may be attributed to the increasing number of sulpher vacancies present in the sample. In both the temperature regions, the d.c. electrical conductivity for the thin films can be expressed by the usual relation

$$
\sigma_{f}=\sigma_{0} \exp \left(-\frac{\Delta E}{k T}\right)
$$

where, $\Delta E$ is the activation energy, $k$ is the Boltzmann constant and $\sigma_{0}$ is the preexponential factor. Following this relation, the activation energy $(\Delta E)$ of the carriers for high temperature region was calculated from the slope of the plots. The values obtained are given in Table 3. The nature of the variation of conductivity with temperature suggests that more than one type of conduction is involved in CdS.

Table 3. Variation of activation energy with thickness.

\begin{tabular}{cc}
\hline Film thickness in $\mathrm{nm}$ & Activation energy $\Delta$ Ein $\mathrm{eV}$ \\
\hline 110 & 0.078 \\
175 & 0.055 \\
190 & 0.050 \\
250 & 0.047 \\
\hline
\end{tabular}

In the low temperature region it shows metallic behavior and the conductivity decreases with the increasing temperature. This reduction in conductivity is due to the various types of scattering of carriers. In the high temperature region a phase change seems to occur and CdS shows semiconducting property. The activation energies are quite low. These low activation energies may be associated with hoping of carriers between the localized levels.

\section{CONCLUSION}

CdS thin films were prepared onto glass substrate keeping the substrate temperature $573 \mathrm{~K}$ by spray pyrolysis method. Different physical properties such as optical and 
electrical properties as well as surface morphology have been studied. The SEM micrographs of as-deposited film showed uniform deposition over the substrate. The absorption coefficient found obtained to be $80 / \mathrm{m}$ at the higher energy region (lower wavelength region) and the rate of absorption was maximum near the absorption edge at around $500 \mathrm{~nm}$. The electrical measurements were made on the deposited films from the room temperature to $553 \mathrm{~K}$. The resistivity is found in the order of $10^{-4} \mathrm{Ohm}-\mathrm{cm}$ at room temperature. In this study, the results obtained from optical and electrical as well as surface micrographs are found to be in good agreement with the reported results. Although the spray pyrolysis method is an old technique but still it is useful for synthesis of quality thin films at low cost for both academic and scientific interest.

\section{ACKNOWLEDGEMENTS}

The authors are thankful to the Chairman of the Department of Physics, BUET for providing facilities to conduct this research. The authors are also thankful to the Materials Science Division, AECD for providing data of SEM and EDX and to Department of Applied Physics \& Electronics Engineering, University of Rajshahi, for Electrical measurements.

\section{REFERENCES}

Anuar, K., S. N. Ho, W. T. Tan, M. S. Atan, D. Kuang, H. M. Jelas and N. Saravanan. 2008. Effects of solution concentration on the properties of $\mathrm{Cu}_{4} \mathrm{SnS}_{4}$ Thin Films. Materials science 14(2): 20-29.

Bagnall, D. M., B. Ullrich, H. Sakai and Segawa. 2001. Micro-cavity lasing of optically excited Cds thin films at room temperature. J. Crystal Growth 214: 1015-1018.

Elangovan, E. and K. Ramamurthi. 2009. Studies on optical properties of polycrystalline $\mathrm{SnO}_{2}: \mathrm{Sb}$ thin films prepared using $\mathrm{SnCl}_{2}$ precursor. Cryst. Res. Technol. 38(9): 779-784.

Hong, N. H., J. Sakai, W. Prellier and A. Hassini. 2005. Transparent Cr-doped $\mathrm{SnO}_{2}$ thin films ferromagnetism beyond room temperature with a giant magnetic moment. J. Phys. Condens. Matter 17(2): 1697-1702.

Jachon, J., M. Varghes and K. E. Abraham. 2007. Studies on $\mathrm{Cu}, \mathrm{Fe}$, and $\mathrm{Mn}$-doped $\mathrm{SnO}_{2} \mathrm{Semi}$ conducting Transparent Films Prepared by a Vapor Deposition Technique. Chinise J. Physics 45(1): 84-97.

Jong-Baek, S., L. Sangyoon and M. Jong. 2009. Spin-coated CdS Thin Films for n-Channel Thin Film Transistors. J. Amer. Chemical Soc. 14: 604-611.

Korotcenkov, G., V. Brinzari and I. Boris. 2008. (Cu, Fe, Co, or Ni)-doped tin dioxide films deposited by spray pyrolysis: doping influence on film morphology. J. Mater. Sci. 43(1): 2761-2770.

Lozada-Morales, R. and O. Zelaya-Ange. 2004. Effects of annealing on the lattice parameter of polycrystalline CdS thin films. Cryst. Res. Technol. 39: 1115-1120.

Morales-Acevedo, A. Vigil-Galan, O. Contreras-Puente, G. Vidal-Larramendi, J. Arriaga-Mejia, G. Chavarria-Castaheda, M. Escamilla-Esquivel, A. Hernandez-Contreras, H. Arias-Carbajal and A. Cruz-Gandarilla. 2008. Physical properties of CdS thin films grown by different techniques: A comparative study. Proc. Photovoltaic Specialists Conf. 15: 624- 627. 
Naumov, A. V., T. G. Bolgova, V. N. Semenov, T. L. Maiorova and V. G. Klyuev. 2006. Luminescence and photoconductivity of alkali-metal-doped cadmium sulfide films. $J$. Inorganic Materials 42(5): 463-469.

Takahashi, M., S. Hasegawa, M. Watanabe, T. Miyuki, S. Ikeda and K. Iida. 2002. Preparation of $\mathrm{CdS}$ thin films by electrodeposition: effect of colloidal sulfur particle stability on film composition. Journal of Applied Electrochemistry 32(4): 359-367.

Vazquez-Luna, J., G. Zehe, M. P. Trujillo-Garcia. and O. Starostenko. 2007. Formation of CdS thin films in a chemical bath environment under the action of an external magnetic field. Russian $J$. Electrochem. 36(8): 893-897.

(Received revised manuscript on 10 February, 2013) 